\title{
The association between creativity and 7R polymorphism in the dopamine receptor D4 gene (DRD4)
}

\author{
Naama Mayseless ${ }^{1}$, Florina Uzefovsky ${ }^{2}$, Idan Shalev ${ }^{3}$, Richard P. Ebstein ${ }^{2,4}$ and Simone G. Shamay-Tsoory ${ }^{1}$ \\ Department of Psychology, University of Haifa, Haifa, Israel \\ ${ }^{2}$ Department of Psychology, The Hebrew University of Jerusalem, Jerusalem, Israel \\ ${ }^{3}$ Department of Human Genetics, Hadassah-Hebrew University of Jerusalem, Jerusalem, Israel \\ ${ }^{4}$ Department of Psychology, National University of Singapore, Singapore
}

\section{Edited by:}

Zbigniew R. Struzik, The University of

Tokyo, Japan

Reviewed by:

Bernhard Hommel, Leiden University, Netherlands

Hikaru Takeuchi, Tohoku University, Japan

${ }^{*}$ Correspondence:

Naama Mayseless, Department of Psychology, University of Haifa, 31905

Mount Carmel, Haifa, Israel

e-mail: naama27@gmail.com
Creativity can be defined as the ability to produce responses that are both novel and appropriate. One way to assess creativity is to measure divergent thinking (DT) abilities that involve generating multiple novel and meaningful responses to open-ended questions. DT abilities have been shown to be associated with dopaminergic (DA) activity, and impaired DT has been reported in populations with DA dysfunctions. Given the strong association between DT and the DA system, the current study examined a group of healthy individuals ( $N=185$ ) to determine the role of repeat polymorphism in exon3 of the DRD4 gene in creativity. The results show that individuals carrying the DRD4-7R allele scored significantly lower on tests of DT, particularly on the flexibility dimension of DT, compared to non-carriers. The current findings link creative cognition to the DA system and suggest that DA dysfunctions in neurological and psychiatric disorders may account for impaired creativity and cognitive flexibility in these individuals.

Keywords: DRD4, creativity, flexibility, divergent thinking, dopamine

\section{INTRODUCTION}

Creative cognition plays an important role in the arts, in invention and innovation, as well as in everyday life (Runco and Richards, 1997). Although creativity has been considered a unique human capacity, spontaneously creative behaviors (e.g., creating new tools among primates and birds) have been shown to occur in non-humans as well (Byrne and Bates, 2007), further attesting to creativity's deep evolutionary and biological roots. Creativity has been defined as the ability to produce responses that are both novel (i.e., original, rare and unexpected) and suitable (i.e., adaptive and useful according to task constraints) (Sternberg and Lubart, 1999). One of the psychometric approaches to measuring creativity involves divergent thinking (DT) tasks in which participants are asked to respond to a given problem with multiple solutions (Dietrich and Kanso, 2010). Tests of DT generally measure various aspects of creativity, including creative fluency, flexibility and originality (Torrance, 1974). Thus, although not synonymous with creativity, DT tasks provide structured and objective measurements of creativity (Sternberg and Lubart, 1999; Jung et al., 2009). Notably, scores on DT tasks have been shown to be positively correlated with ecologically valid measures of creative achievement (Carson et al., 2005) as well as with self-rated creativity (Furnham and Bachtiar, 2008).

Previous studies have pointed to the involvement of the dopaminergic (DA) system in creativity (Heilman et al., 2003; Flaherty, 2005; Takeuchi et al., 2010). Takeuchi et al. (2010) found individual differences in creativity, as measured by DT, to be positively correlated with grey matter in DA system regions, including the dorsolateral prefrontal cortex, bilateral basal ganglia, substantia nigra, and the tegmental ventral area. Additionally, several genetic studies have shown a relationship between DT and dopamine neurotransmission (Reuter et al., 2006; De Manzano et al., 2010; Runco et al., 2011). For example, Reuter et al. (2006) found creativity, as measured by DT tasks involving both figural and verbal creativity, to be significantly associated with polymorphisms of the dopamine D2 receptor gene (DRD2). Moreover, several studies have found cortical dopamine to be involved in cognitive flexibility (Frank, 2005; Cools, 2008; Garcia-Garcia et al., 2010), one of the main components of DT.

One interesting DA candidate gene for creativity is the dopamine D4 receptor gene (DRD4). The DRD4 receptor is one of five dopamine receptors and plays an important role in mediating synaptic dopamine signaling. The gene is characterized by a 48 base-pair variable number of tandem repeats (48-bp VNTR) located in the coding region of the third exon. DRD4 48-bp VNTR polymorphism varies from 2 to 11 repeats across individuals (Asghari et al., 1995; Cravchik and Goldman, 2000), where the 4-repeat (4R) is the most common repeat in Caucasian populations and the 7-repeat $(7 \mathrm{R})$ is the second most common variant (Chang et al., 1996; Ding et al., 2002). Interestingly, the $7 \mathrm{R}$ has been previously associated with real-life creative behaviors, such as the novelty-seeking personality trait (Ebstein et al., 1996). Indeed, novelty-seeking-the tendency toward exploratory activity-is thought to be one of the characteristics of creative people (Chavez-Eakle et al., 2006; Drago et al., 2009). Although the evidence for an association between DRD4 7R and novelty-seeking is inconsistent, as evidenced by several 
meta-analysis reports (Kluger et al., 2002; Munafò et al., 2008), many studies have found a significant association between novelty-seeking and the 7R allele of the DRD4 (Ebstein et al., 1996; Benjamin et al., 2000; Keltikangas-Järvinen et al., 2002; Becker et al., 2005). Roussos et al. (2009) have recently suggested that differences in measuring novelty-seeking using self-report scales may account for the inconsistent results between $7 \mathrm{R}$ polymorphism and novelty-seeking. In line with this, it has been repeatedly found that the DA system plays a major role in the personality trait of novelty-seeking (Flaherty, 2005; Schweizer, 2006), further attesting to the potential role of DRD4 in creativity.

Nonetheless, in contrast to the role of DRD4 48-bp VNTR 7R in novelty-seeking, recent evidence indicates that $7 \mathrm{R}$ is actually associated with impaired cognitive flexibility, one of the major aspects of creativity (Strobel et al., 2004; Congdon et al., 2008). Flexibility involves the ability to make an alternative response after successfully inhibiting a current response. Findings so far on the association between inhibition and DRD4 are mixed. Congdon et al. (2008) found that participants with the $7 \mathrm{R}$ allele of the DRD4 exhibit higher stop-signal reaction time (SSRT) on a go/no-go task, reflecting poorer inhibitory control, while Forbes et al. (2009) failed to find such an effect on the Barratt Impulsiveness Scale (BIS), a self-report tool to measure impulsivity. On the other hand, Colzato et al. (2010) demonstrated that these mixed effects may be due to the fact that previous studies addressed impulsivity as a monolithic process, while impulsivity may actually be divided into functional and dysfunctional types according to Dickman's Impulsivity Inventory (DII; Dickman, 1990). Dysfunctional impulsivity is the tendency to act without forethought in cases when such action is inappropriate, while functional impulsivity is a similar tendency implemented in appropriate situations (Colzato et al., 2010). Colzato et al. (2010) found that individuals with DRD4 7R, which is associated with higher levels of striatal DA, exhibited higher dysfunctional impulsivity. Several meta-analytical studies have pointed to the $7 \mathrm{R}$ allele of the DRD4 as a risk allele for attention-deficit hyperactivity disorder (ADHD; Faraone et al., 2001; DiMaio et al., 2003), a disorder characterized by high dysfunctional impulsivity (Young et al., 2007). Furthermore, the relationship between ADHD and creativity has been investigated in several studies (Shaw and Brown, 1990; Healey and Rucklidge, 2006), though so far these studies have yielded unclear results. While some have found ADHD and its symptomology to be positively correlated with creativity (Healey and Rucklidge, 2006; White and Shah, 2011), others have reported an opposite trend (Funk et al., 1993; Healey and Rucklidge, 2005, 2008). Interestingly, ADHD is behaviorally associated with impairments in executive control, including attentional set-shifting (Boonstra et al., 2005), and flexibility (Barkley et al., 1997; Sergeant et al., 2002), both of which are important for cognitive flexibility, a central dimension of creativity (Dietrich, 2004; Durstewitz and Seamans, 2008). These findings indicate that individuals with the 7R allele of the DRD4 may exhibit lower levels of creativity and diminished flexibility on DT tasks in particular. Hence, the DRD4 exon III VNTR is a biologically plausible candidate for contributing to individual differences in creativity.
Collectively, it appears that on the one hand the 7R allele, as a risk allele for impaired executive functions, flexibility and set shifting, may be associated with low creativity. On the other hand, the association between the 7R allele and higher novelty-seeking indicates that individuals with the $7 \mathrm{R}$ allele may actually exhibit greater flexibility and creativity.

The current study was designed to explore the complex role of the DRD4 7R in partially shaping human creativity. To better characterize this relationship, we assessed two types of DT tests (figural and verbal). The scoring of each task was divided according to the three main dimensions of DT, namely creative fluency, flexibility and originality, and each dimension was analyzed separately to test the hypothesis that DRD4 differentially affects each dimension of creativity.

\section{METHOD \\ PARTICIPANTS}

The sample comprised 185 students from the University of Haifa in Israel (112 female). All participants were Caucasian (selfreported), with a mean age of $24.5(\mathrm{SD} \pm 2.1)$. Participants were recruited through announcements posted at the university. All participants were paid volunteers.

\section{ASSESSMENT OF CREATIVITY}

Creativity was assessed using two DT tests, a sub-scale from the figural sub-test of the Torrance test of creative thinking (Torrance, 1974), and the Alternate Uses Task (AUT; Guilford et al., 1978). Both tests included the three core dimensions of DT, namely flexibility, originality and fluency.

\section{TORRANCE TEST OF CREATIVE THINKING (CIRCLES SUB-SCALE)}

Participants were given a page on which 30 identical circles were drawn. They were asked to draw as many different meaningful objects as possible within a time limit of $10 \mathrm{~min}$, where each drawing must include at least one circle. Scoring included fluency (number of answers produced), flexibility (number of categories) and originality, calculated according to the scoring of original responses, as detailed in the Torrance Tests of Creative Thinking scoring guide (Torrance, 1974).

\section{ALTERNATE USES TASK (AUT)}

Participants were given a list of five common objects and asked to list as many alternate uses as possible for each object, within a time limit of $10 \mathrm{~min}$. The most common everyday use was indicated in parenthesis. The objects were: shoe (common use: wear on foot); button (common use: closing things); pencil (common use: drawing or writing); tire (common use: car wheel); and drinking glass (common use: contains liquid). Only responses that did not reiterate the given common uses were counted and included. As in the Torrance test, scoring included fluency, flexibility and originality. Since there are no guidelines for the scoring of original responses in the AUT, original responses were defined as statistically infrequent responses according to a pretest conducted in our lab.

\section{PRETEST}

For the purpose of creating a valid criterion of response frequency, a group of 100 healthy participants who did not take part in this 
study completed the AUT. For each object, a list of all possible uses was collected from all participants. A statistical infrequency measure was calculated based on this list in order to evaluate the originality score for each answer, and, subsequently, for each participant. Answers were assigned a score of zero if 5\% or more of the participants listed a given use, a score of one if between $2 \%$ and $4.99 \%$ of participants listed it, and a score of two if less than $1.99 \%$ listed the use. An average originality score was calculated for each participant according to these statistical infrequency scores.

\section{DNA extraction and genotyping}

DNA was extracted from $20 \mathrm{ml}$ of mouthwash samples using the Master Pure kit (Epicentre, Madison, WI). The DRD4 48bp VNTR was characterized by a PCR amplification procedure with the following primers: F5' - CTT CCT ACC CTG CCC GCT CAT GCT GCTGCT CTA CTGG - 3' and R5' - ACC ACCACC GGC AGG ACC CTC ATG GCC TTG CGC TC - 3. PCR reactions were conducted using $5 \mu \mathrm{l}$ Master Mix (Thermo scientific), 2 $\mu \mathrm{l}$ primers $(0.5 \mu \mathrm{M}), 0.6 \mu \mathrm{l} \mathrm{Mg} / \mathrm{Cl} 2(2.5 \mathrm{mM}), 0.4 \mu \mathrm{l} \mathrm{DMSO}$ $5 \%$ and $1 \mu \mathrm{l}$ of water to a total of $9 \mu \mathrm{l}$ total volume, and an additional $1 \mu$ l of genomic DNA was added to the mixture. All PCR reactions were carried out on a Biometra T1 Thermocycler (Biometra, Güttingem, Germany). The PCR reaction condition was as follows: preheating step at $94.0^{\circ} \mathrm{C}$ for $5 \mathrm{~min}, 34$ cycles of denaturation at $94.0^{\circ} \mathrm{C}$ for $30 \mathrm{~s}$, reannealing at $55^{\circ} \mathrm{C}$ for $30 \mathrm{~s}$, and extension at $72^{\circ} \mathrm{C}$ for $90 \mathrm{~s}$. The reaction proceeded to hold at $72^{\circ} \mathrm{C}$ for $5 \mathrm{~min}$. The reaction mixture was then electrophoresed on a $3 \%$ agarose gel (AMRESCO) with ethidium bromide to screen for genotypes.

The distribution of genotype frequency was according to the Hardy-Weinberg equilibrium (chi-square $=0.01, p$ value $=0.92$ ).

\section{STATISTICAL ANALYSIS}

Genotype was classified according to the presence or absence of the 7R allele of the DRD4 (7 vs. no7), as in line with previous reports in the literature (Ding et al., 2002). Group differences on creativity scores were analyzed statistically using ANOVAs, with the presence (7) or absence (no7) of the DRD4 7R allele as the independent variable. To examine the different aspects of DT (fluency, flexibility, originality), we conducted a multivariate analysis of variance (MANOVA) separately for each component.

\section{RESULTS}

To confirm that the two groups $(7$, no7) were not significantly different in terms of age and education, we conducted independent t-tests to compare the two groups (see Table 1 for means and standard deviations). This analysis revealed that the

Table 1 | Age, gender and education data for the DRD4 7R genotype, SD: standard deviation.

\begin{tabular}{|c|c|c|c|c|c|c|}
\hline & \multirow[t]{2}{*}{$\mathbf{N}$} & \multirow[t]{2}{*}{ Female (percent) } & \multicolumn{2}{|c|}{ Age (years) } & \multicolumn{2}{|c|}{ Education (years) } \\
\hline & & & Mean & SD & Mean & SD \\
\hline no7 & 128 & 65.63 & 24.54 & 2.2 & 13.83 & 1.27 \\
\hline 7 & 57 & 49.12 & 24.67 & 2.02 & 13.82 & 1.16 \\
\hline
\end{tabular}

two groups did not differ in terms of age or years of education. Non-parametric tests (Mann-Whitney) revealed significant differences in the frequency distribution for gender $(Z=2.11$, $p<0.05)$.

The mean scores of the creativity measures used in the two tasks are summarized in Table 2.

\section{THE FLUENCY COMPONENT}

A multivariate ANOVA indicated a general effect of DRD4 7R genotype for the fluency component, $F(2,182)=3.25, p<0.05$. Given the significance of the overall test, univariate main effects were examined. Significant univariate main effects for DRD4 genotype were obtained for AUT fluency $F(1,183)=4.95, p<0.05$ (7R allele exhibiting lower fluency compared to the no7 group, Figure 1A), but did not reach the level of significance for Torrance fluency $F(1,183)=2.95, p=0.087$.

\section{THE FLEXIBILITY COMPONENT}

Multivariate ANOVA of the flexibility measures exhibited a general effect for DRD4 7R genotype $F(2,182)=4.38, p<0.05$. Significant univariate main effects for DRD4 genotype were obtained for AUT flexibility $F(1,183)=4.57, p<0.05$ and for Torrance flexibility $F(1,183)=6.95, p<0.01$. As shown in Figure $1 \mathbf{B}$, in both cases individuals in the $7 \mathrm{R}$ allele group exhibited lower flexibility compared to individuals in the no7 group (Table 2).

\section{THE ORIGINALITY COMPONENT}

Multivariate ANOVA of the originality measures did not exhibit any significance effects, $F(2,182)=2.06, p=0.13$, although the scores did indicate lower originality for the $7 \mathrm{R}$ allele of the DRD4 (see Figure 1C, Table 2 for details).

\section{GENDER DIFFERENCES}

Because gender distribution differed significantly between the two DRD4 7R groups, we re-analyzed the multivariate ANOVA's, with gender as an additional independent between-subject variable. These analyses did not indicate any interaction effects for gender and DRD4 genotype, either for fluency $(F(2,180)=0.81, p=0.45)$ or for flexibility $(F(2,180)=1.55, p=0.21)$. Adding gender as an independent variable rendered the main effect of DRD4 genotype on fluency as not significant, $F(2,180)=2.73, p=0.068$, but did not change the significance of the effect for flexibility, $F(2,180)=$ $3.39, p<0.05$. There were no significant main effects for gender either on fluency $(F(2,180)=2.79, p=0.064)$ or on flexibility $(F(2,180)=1.63, p=0.19)$.

Table 2 | Means and Standard Error (SE) of the two creativity tasks used: AUT and Torrance

\begin{tabular}{|c|c|c|c|c|c|}
\hline & & \multicolumn{2}{|c|}{7} & \multicolumn{2}{|c|}{ no7 } \\
\hline & & Mean & SE & Mean & SE \\
\hline \multirow[t]{2}{*}{ Fluency } & Torrance & 12.77 & 0.69 & 14.35 & 0.53 \\
\hline & AUT & 3.72 & 0.17 & 4.24 & 0.13 \\
\hline \multirow[t]{2}{*}{ Flexibility } & Torrance & 8.74 & 0.39 & 10.39 & 0.38 \\
\hline & AUT & 3.36 & 0.15 & 3.78 & 0.11 \\
\hline \multirow[t]{2}{*}{ Originalty } & Torrance & 27.37 & 1.28 & 31.07 & 1.10 \\
\hline & AUT & 2.50 & 0.20 & 2.83 & 0.17 \\
\hline
\end{tabular}




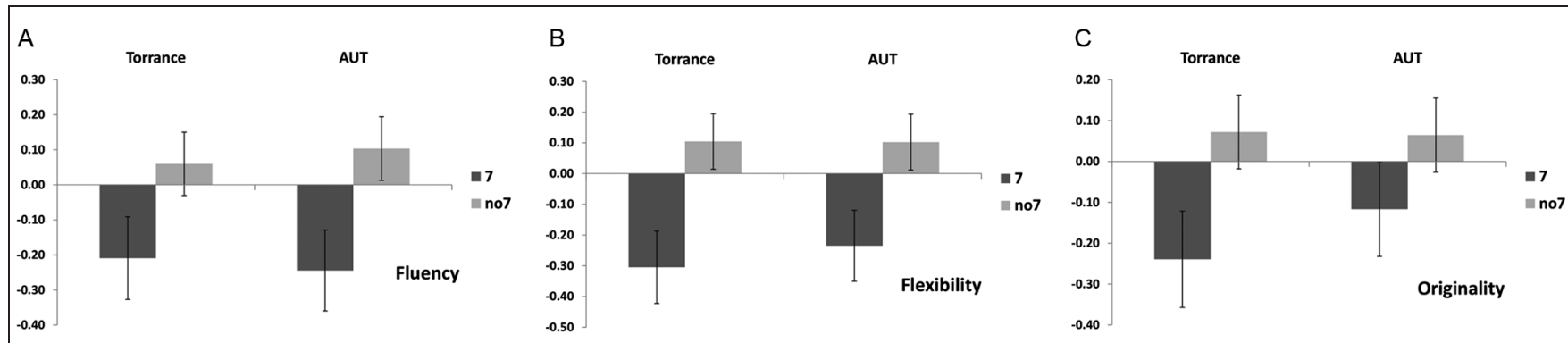

FIGURE 1 | Creativity scores on the AUT and Torrance tasks separated to fluency (A), flexibility (B) and originality (C). Means were transformed into Z scores.

\section{DISCUSSION}

DT tasks require participants to provide multiple solutions to a given problem. In the tasks used here, participants were required to think of many alternate possible uses for everyday items (in the AUT), and to draw multiple drawings incorporating a specific shape (circle) (in the Torrance task). The results presented here demonstrate that individuals with the DRD4 7R allele exhibit lower creativity as measured by DT. Considering that the $7 \mathrm{R}$ allele has been associated with dysfunctional impulsivity and poor inhibition (Congdon et al., 2008; Dreber et al., 2009), the fact that individuals with the $7 \mathrm{R}$ allele exhibit lower creativity can be explained by their inability to suppress or inhibit obvious (common) responses, as indicated by lower originality scores. Lower flexibility and fluency scores may indicate that once a common response has been given, it becomes harder to shift to a new category (as indicated by the low flexibility scores), leading to fewer responses (as indicated by the low fluency score). Further evidence for the relationship between creativity and impulsivity can be seen in the association of the 7R allele with ADHD (Li et al., 2006), as well as with increased impulsivity in ADHD patients (Langley et al., 2004). Interestingly, creativity has been linked to the DA system in the case of schizophrenia (Eysenck, 1993). Although several studies show that patients with schizophrenia and schizotypal personality exhibit high creativity (O'Reilly et al., 2001; Folley and Park, 2005), recent models of schizophrenia and creativity support an inverted $\mathrm{U}$-shaped association in which creativity may be higher with low-moderate schizotypal trait, but decreases as the severity of psychopathology in schizophrenia increases (Tsakanikos and Claridge, 2005; Stoneham and Coughtrey, 2009; Nelson and Rawlings, 2010). Indeed, in a recent study Jaracz et al. (2012) reported that patients with schizophrenia show diminished creativity compared to controls. Furthermore, the authors reported that impaired creativity was associated with low cognitive flexibility and impulsivity, reflected by their low scores on the Wisconsin Card Sorting Test (WCST). These results are in line with previous research showing that patients with chronic schizophrenia exhibit lower creativity, which in the case of creative fluency was mediated by scores on executive control tasks and in the case of originality was not (Abraham et al., 2007). Collectively, while mild functional impulsivity may improve creativity among patients with schizotypal traits, espe- cially in generating ideas which differ from the examples given (Abraham and Windmann, 2008), the dysfunctional impulsivity observed in severe schizophrenia may dampen creative abilities.

The results of the current study support the relationship between creativity and variants of DA genetic polymorphisms (Reuter et al., 2006; Runco et al., 2011). Moreover, the results found in our sample indicate that the main effect of the DRD4-7R allele on creativity may be due to its impact on flexibility. Several studies have linked cognitive flexibility with DA pathways (Ashby and Isen, 1999; Dreisbach and Goschke, 2004; Müller et al., 2007). It has been postulated that activation of D2-like receptors (i.e., D2, D3 and D4) decreases GABAergic inhibition and facilitates activation of multiple representations, thus increasing flexibility as manifested by set-shifting abilities (Müller et al., 2007; Seamans and Robbins, 2010). Moreover, D2-like receptors have been linked to flexible integration of new information (Durstewitz and Seamans, 2008). In line with this, Reuter et al. (2006) found an association between the dopamine receptor D2 and creativity as measured by a composite index, though whether flexibility played a major role in these results cannot be determined. Additionally, Runco et al. (2011) reported differences in creative fluency among carriers of several dopamine genes, among them the DRD4. However, it is not clear from their report which group exhibits greater creative abilities. It is important to note that as opposed to the results presented here, Runco et al. (2011) did not find an association between measures of flexibility as measured by DT tasks and DRD4. This inconsistency may be explained by differences in the populations used and the group sizes or by differences in allele frequencies within the sampled population. Furthermore, there is evidence suggesting that the association between dopamine and DT may not be a linear one (Akbari Chermahini and Hommel, 2010, 2012), indicating that an interaction among several DA genes may influence the individual results of each genetic variability in the context of DT. In addition, several studies have pointed to the fact that DA pathways may be gender sensitive (Tammimäki and Männistö, 2011; Wang et al., 2012). Zhong et al. (2010), for example, found that gender modulated the association between DRD4 exon3 polymorphism and sense of fairness. In the current study we did not find an interaction effect between the DRD4-7R and gender, indicating that gender does not have a modulating effect on the association between DRD4 
and creativity in our sample. Furthermore, the results presented here indicate a lack of gender differences in creativity, and in DT in particular (for review, see Baer and Kaufman, 2008).

In conclusion, in the current study we suggest that the association found between DRD4 and creativity is mainly influenced by flexibility. The results of the current study are in line with previous results pointing to the involvement of the DA system in creativity and add to the accumulating body of knowledge suggesting genetic influences in creativity.

There are several limitations of the study that should be acknowledged. First, the current study only examined the association between one genetic variability in the DA system-the DRD4-and DT. However, there are other important polymorphisms in the striatal DA system that could be associated with DT

\section{REFERENCES}

Abraham, A., and Windmann, S. (2008). Selective information processing advantages in creative cognition as a function of schizotypy. Creat. Res. J. 20, 1-6. doi: 10. 1080/10400410701839819

Abraham, A., Windmann, S., Mckenna, P., and Güntürkün, O. (2007). Creative thinking in schizophrenia: the role of executive dysfunction and symptom severity. Cogn. Neuropsychiatry 12, 235-258. doi: 10. 1080/13546800601046714

Akbari Chermahini, S., and Hommel, B. (2010). The (b) link between creativity and dopamine: spontaneous eye blink rates predict and dissociate divergent and convergent thinking. Cognition 115, 458-465. doi: 10. 1016/j.cognition.2010.03.007

Akbari Chermahini, S., and Hommel, B. (2012). More creative through positive mood? Not everyone! Front. Hum. Neurosci. 6:319. doi: 10. 3389/fnhum.2012.00319

Asghari, V., Sanyal, S., Buchwaldt, S., Paterson, A., Jovanovic, V., and Van Tol, H. H. (1995). Modulation of intracellular cyclic AMP levels by different human dopamine D4 receptor variants. J. Neurochem. 65, 1157-1165. doi: 10.1046/j.14714159.1995.65031157.x

Ashby, F. G., and Isen, A. M. (1999). A neuropsychological theory of positive affect and its influence on cognition. Psychol. Rev. 106, 529550. doi: 10.1037/0033-295x.106. 3.529

Baer, J., and Kaufman, J. C. (2008). Gender differences in creativity. $J$. Creat. Behav. 42, 75-105. doi: 10. 1002/j.2162-6057.2008.tb01289.x

Barkley, R. A., Koplowitz, S., Anderson, T., and Mcmurray, M. B. (1997). Sense of time in children with ADHD: effects of duration, distrac- tion, and stimulant medication. J. Int. Neuropsychol. Soc. 3, 359-369.

Becker, K., Laucht, M., El-Faddagh, M., and Schmidt, M. (2005). The dopamine D4 receptor gene exon III polymorphism is associated with novelty seeking in 15-year-old males from a high-risk community sample. J. Neural Transm. 112, 847-858. doi: 10.1007/s00702-004-0223-y

Benjamin, J., Osher, Y., Kotler, M., Gritsenko, I., Nemanov, L., Belmaker, R., et al. (2000). Association between tridimensional personality questionnaire (TPQ) traits and three functional polymorphisms: dopamine receptor D4 (DRD4), serotonin transporter promoter region (5-HTTLPR) and catechol O-methyltransferase (COMT). Mol. Psychiatry 5, 96-100. doi: 10. 1038/sj.mp.4000640

Boonstra, A. M., Oosterlaan, J., Sergeant, J. A., and Buitelaar, J. K. (2005). Executive functioning in adult ADHD: a meta-analytic review. Psychol. Med. 35, 1097-1108. doi: 10.1017/S003329170500499X

Byrne, R. W., and Bates, L. A. (2007). Sociality, evolution and cognition. Curr. Biol. 17, R714-R723. doi: 10. 1016/j.cub.2007.05.069

Carson, S. H., Peterson, J. B., and Higgins, D. M. (2005). Reliability, validity, and factor structure of the creative achievement questionnaire. Creat. Res. J. 17, 37-50. doi: 10. 1207/s15326934crj1701_4

Chang, F.-M., Kidd, J. R., Livak, K. J., Pakstis, A. J., and Kidd, K. K. (1996). The world-wide distribution of allele frequencies at the human dopamine D4 receptor locus. Hum. Genet. 98, 91-101. doi: 10.1007/s004390050166

Chavez-Eakle, R. A., Del Carmen Lara, M., and Cruz-Fuentes, C. (2006). Personality: a pos-

and may contribute both in a standalone manner as well as in gene-gene interactions. One such polymorphism is the dopamine transporter (DAT1), which has been shown to be associated with inhibition of return (Colzato et al., 2010) as well as with measures of impulsivity (Gizer and Waldman, 2012). Furthermore, as mentioned above, another possibility that was not explored here is the possible gene-gene interaction effects on DT. Akbari Chermahini and Hommel (2010) reported a nonlinear association between a marker of striatal dopamine and DT, indicating that the relation may be more complex, such that one polymorphism of a gene may impact DT through the mediation of another gene polymorphism. Thus, future studies should consider examining the interaction between these two polymorphisms in the context of flexibility and DT.

sible bridge between creativity and psychopathology? Creat. Res. J. 18, 27-38. doi: 10. 1207/s15326934crj1801_4

Colzato, L., Van Den Wildenberg, W. Van Der Does, A., and Hommel, B. (2010). Genetic markers of striatal dopamine predict individual differences in dysfunctional, but not functional impulsivity. Neuroscience 170, 782-788. doi: 10.1016/j. neuroscience.2010.07.050

Congdon, E., Lesch, K. P., and Canli, T. (2008). Analysis of DRD4 and DAT polymorphisms and behavioral inhibition in healthy adults: implications for impulsivity. Am. J. Med. Genet. B Neuropsychiatr. Genet. 147, 27-32. doi: 10.1002/ajmg.b. 30557

Cools, R. (2008). Role of dopamine in the motivational and cognitive control of behavior. $\mathrm{Neu}$ roscientist 14, 381-395. doi: 10 . 1177/1073858408317009

Cravchik, A., and Goldman, D. (2000). Neurochemical individuality: genetic diversity among human dopamine and serotonin receptors and transporters. Arch. Gen. Psychiatry 57, 1105-1114. doi: 10. 1001/archpsyc.57.12.1105

De Manzano, Ö., Cervenka, S., Karabanov, A., Farde, L., and Ullén, F. (2010). Thinking outside a less intact box: thalamic dopamine D2 receptor densities are negatively related to psychometric creativity in healthy individuals. PLoS One 5:e10670. doi: 10.1371/journal. pone. 0010670

Dickman, S. J. (1990). Functional and dysfunctional impulsivity: personality and cognitive correlates. J. Pers. Soc. Psychol. 58, 95-102. doi: 10. 1037/0022-3514.58.1.95

Dietrich, A. (2004). The cognitive neuroscience of creativity. Psychon.
Bull. Rev. 11, 1011-1026. doi: 10. 3758/BF03196731

Dietrich, A., and Kanso, R. (2010). A review of EEG, ERP, and neuroimaging studies of creativity and insight. Psychol. Bull. 136, 822-848. doi: 10.1037/a0019749

DiMaio, S., Grizenko, N., and Joober, R. (2003). Dopamine genes and attention-deficit hyperactivity disorder: a review. J. Psychiatry Neurosci. 28, 27-38.

Ding, Y.-C., Chi, H.-C., Grady, D. L., Morishima, A., Kidd, J. R., Kidd, K. K., et al. (2002). Evidence of positive selection acting at the human dopamine receptor D4 gene locus. Proc. Natl. Acad. Sci. U S A 99, 309314. doi: 10.1073/pnas.012464099

Drago, V., Foster, P., Skidmore, F., and Heilman, K. (2009). Creativity in Parkinson's disease as a function of right versus left hemibody onset. J. Neurol. Sci. 276, 179-183. doi: 10. 1016/j.jns.2008.09.026

Dreber, A., Apicella, C. L., Eisenberg, D. T., Garcia, J. R., Zamore, R. S., Lum, J. K., et al. (2009). The 7R polymorphism in the dopamine receptor D4 gene (DRD4) is associated with financial risk taking in men. Evol. Hum. Behav. 30, 85-92. doi: 10. 1016/j.evolhumbehav.2008.11.001

Dreisbach, G., and Goschke, T. (2004). How positive affect modulates cognitive control: reduced perseveration at the cost of increased distractibility. J. Exp. Psychol. Learn. Mem. Cogn. 30, 343-353. doi: 10. 1037/0278-7393.30.2.343

Durstewitz, D., and Seamans, J. K. (2008). The dual-state theory of prefrontal cortex dopamine function with relevance to catecholo-methyltransferase genotypes and schizophrenia. Biol. Psychiatry 64, 739-749. doi: 10.1016/j.biopsych. 2008.05.015 
Ebstein, R. P., Novick, O., Umansky, R., Priel, B., Osher, Y., Blaine, D., et al. (1996). Dopamine D4 receptor (D4DR) exon III polymorphism associated with the human personality trait of novelty seeking. Nat. Genet. 12, 78-80. doi: 10. 1038/ng0196-78

Eysenck, H. J. (1993). Creativity and personality: suggestions for a theory. Psychol. Inq. 4, 147-178. doi: 10 . 1207/s15327965pli0403_1

Faraone, S. V., Doyle, A. E., Mick, E., and Biederman, J. (2001). Metaanalysis of the association between the 7-repeat allele of the dopamine D4 receptor gene and attention deficit hyperactivity disorder. Am. J. Psychiatry 158, 1052-1057. doi: 10. 1176/appi.ajp.158.7.1052

Flaherty, A. W. (2005). Frontotemporal and dopaminergic control of idea generation and creative drive. J. Comp. Neurol. 493, 147-153. doi: 10. 1002/cne.20768

Folley, B. S., and Park, S. (2005). Verbal creativity and schizotypal personality in relation to prefrontal hemispheric laterality: a behavioral and near-infrared optical imaging study. Schizophr. Res. 80, 271-282. doi: 10. 1016/j.schres.2005.06.016

Forbes, E., Brown, S., Kimak, M., Ferrell, R., Manuck, S., and Hariri, A. (2009). Genetic variation in components of dopamine neurotransmission impacts ventral striatal reactivity associated with impulsivity. Mol. Psychiatry 14, 60-70. doi: 10.1038/sj. mp.4002086

Frank, M. J. (2005). Dynamic dopamine modulation in the basal ganglia: a neurocomputational account of cognitive deficits in medicated and nonmedicated Parkinsonism. J. Cogn. Neurosci. 17, 51-72. doi: 10.1162/0898929052880093

Funk, J. B., Chessare, J. B., Weaver, M. T., and Exley, A. R. (1993). Attention deficit hyperactivity disorder, creativity, and the effects of methylphenidate. Pediatrics 91, 816-819.

Furnham, A., and Bachtiar, V. (2008). Personality and intelligence as predictors of creativity. Pers. Individ. Dif. 45, 613-617. doi: 10.1016/j. paid.2008.06.023

Garcia-Garcia, M., Barceló, F., Clemente, I., and Escera, C. (2010). The role of the dopamine transporter DAT1 genotype on the neural correlates of cognitive flexibility. Eur. J. Neurosci. 31, 754-760. doi: 10.1111/j.1460-9568. 2010.07102.x

Gizer, I. R., and Waldman, I. D. (2012). Double dissociation between lab measures of inattention and impulsivity and the dopamine transporter gene (DAT1) and dopamine D4 receptor gene (DRD4). J. Abnorm. Psychol. 121, 1011-1023. doi: 10. 1037/a0028225

Guilford, J., Christensen, P., Merrifield, P., and Wilson, R. (1978). Alternate Uses: Manual of Instructions and Interpretations. Orange, CA: Sheridan Psychological Services.

Healey, D., and Rucklidge, J. J. (2005). An exploration into the creative abilities of children with ADHD. J. Atten. Disord. 8, 88-95. doi: 10. 1177/1087054705277198

Healey, D., and Rucklidge, J. J. (2006). An investigation into the relationship among ADHD symptomatology, creativity, and neuropsychological functioning in children. Child Neuropsychol. 12, 421-438. doi: 10. 1080/09297040600806086

Healey, D. M., and Rucklidge, J. J. (2008). The relationship between ADHD and creativity. ADHD Rep. 16, 1-5. doi: 10.1521/adhd.2008.16. 3.1

Heilman, K. M., Nadeau, S. E., and Beversdorf, D. O. (2003). Creative innovation: possible brain mechanisms. Neurocase 9, 369-379. doi: 10.1076/neur.9.5.369.16553

Jaracz, J., Patrzala, A., and Rybakowski, J. K. (2012). Creative thinking deficits in patients with schizophrenia: neurocognitive correlates. J. Nerv. Ment. Dis. 200, 588-593. doi: 10.1097/NMD. 0b013e31825bfc 49

Jung, R. E., Gasparovic, C., Chavez, R. S., Flores, R. A., Smith, S. M., Caprihan, A., et al. (2009). Biochemical support for the "threshold" theory of creativity: a magnetic resonance spectroscopy study. J. Neurosci. 29, 5319-5325. doi: 10. 1523/JNEUROSCI.0588-09.2009

Keltikangas-Järvinen, L., Elovainio, M., Kivimäki, M., Ekelund, J., and Peltonen, L. (2002). Novelty seeking as a mediator in relationships between type 4 dopamine receptor gene polymorphism and predisposition to higher education. Learn. Individ. Differ. 14, 23-30. doi: 10. 1016/j.lindif.2003.04.001

Kluger, A., Siegfried, Z., and Ebstein, R. (2002). A meta-analysis of the association between DRD4 polymorphism and novelty seeking. Mol. Psychiatry 7, 712-717. doi: 10. 1038/sj.mp.4001082

Langley, K., Marshall, L., Van Den Bree, M., Thomas, H., Owen, M., O'donovan, M., et al. (2004). Association of the dopamine D4 receptor gene 7-repeat allele with neuropsy- chological test performance of children with ADHD. Am. J. Psychiatry 161, 133-138. doi: 10.1176/appi.ajp. 161.1.133

Li, D., Sham, P. C., Owen, M. J., and $\mathrm{He}$, L. (2006). Meta-analysis shows significant association between dopamine system genes and attention deficit hyperactivity disorder (ADHD). Hum. Mol. Genet. 15, 2276-2284. doi: 10. 1093/hmg/ddl152

Müller, J., Dreisbach, G., Brocke, B., Lesch, K.-P., Strobel, A., and Goschke, T. (2007). Dopamine and cognitive control: the influence of spontaneous eyeblink rate, DRD4 exon III polymorphism and gender on flexibility in set-shifting. Brain Res. 1131, 155-162. doi: 10.1016/j. brainres.2006.11.002

Munafò, M. R., Yalcin, B., Willis-Owen, S. A., and Flint, J. (2008). Association of the Dopamine D4 Receptor (DRD4) gene and approach-related personality traits: meta-analysis and new data. Biol. Psychiatry 63, 197 206. doi: 10.1016/j.biopsych.2007. 04.006

Nelson, B., and Rawlings, D. (2010). Relating schizotypy and personality to the phenomenology of creativity. Schizophr. Bull. 36, 388-399. doi: 10. 1093/schbul/sbn098

O’Reilly, T., Dunbar, R., and Bentall, R. (2001). Schizotypy and creativity: an evolutionary connection? Pers. Individ. Dif. 31, 1067-1078. doi: 10. 1016/s0191-8869(00)00204-x

Reuter, M., Roth, S., Holve, K., and Hennig, J. (2006). Identification of first candidate genes for creativity: a pilot study. Brain Res. 1069, 190197. doi: 10.1016/j.brainres.2005 11.046

Roussos, P., Giakoumaki, S. G., and Bitsios, P. (2009). Cognitive and emotional processing in high novelty seeking associated with the L-DRD4 genotype. Neuropsychologia 47, 1654-1659. doi: 10.1016/j. neuropsychologia.2009.02.005

Runco, M. A., Noble, E. P., ReiterPalmon, R., Acar, S., Ritchie, T., and Yurkovich, J. M. (2011). The genetic basis of creativity and ideational fluency. Creat. Res. J. 23, 376380. doi: 10.1080/10400419.2011. 621859

Runco, M. A., and Richards, R. (1997). Eminent Creativity, Everyday Creativity, and Health. Greenwich, CT: Ablex.

Schweizer, T. S. (2006). The psychology of novelty-seeking, creativity and innovation: neurocognitive aspects within a work-psychological perspective. Creat. Innov. Manage. 15,
164-172. doi: 10.1111/j.1467-8691. 2006.00383.x

Seamans, J. K., and Robbins, T. W. (2010). "Dopamine modulation of the prefrontal cortex and cognitive function," in The Dopamine Receptors, ed K. A. Neve (New York, NY: Humana Press), 373-398.

Sergeant, J. A., Geurts, H., and Oosterlaan, J. (2002). How specific is a deficit of executive functioning for attention-deficit/hyperactivity disorder? Behav. Brain Res. 130, 3-28. doi: 10.1016/s0166-4328(01) 00430-2

Shaw, G. A., and Brown, G. (1990). Laterality and creativity concomitants of attention problems. Dev. Neuropsychol. 6, 39-56. doi: 10. 1080/87565649009540448

Sternberg, R. J., and Lubart, T. I. (1999). "The concept of creativity: prospects and paradigms," in Handbook of Creativity, ed R. J. Sternberg (Cambridge: Cambridge University Press), 3-15.

Stoneham, A., and Coughtrey, A. E. (2009). The role of schizotypy and creativity in a group problemsolving task. Pers. Individ. Dif. 46, 827-831. doi: 10.1016/j.paid.2009. 01.014

Strobel, A., Debener, S., Anacker, K., Müller, J., Lesch, K.-P., and Brocke, B. (2004). Dopamine D4 receptor exon III genotype influence on the auditory evoked novelty P3. Neuroreport 15, 2411-2415. doi: 10.1097/00001756-20041025000022

Takeuchi, H., Taki, Y., Sassa, Y., Hashizume, H., Sekiguchi, A., Fukushima, A., et al. (2010). Regional gray matter volume of dopaminergic system associate with creativity: evidence from voxel-based morphometry. $\mathrm{Neu}$ roimage 51, 578-585. doi: 10.1016/j. neuroimage.2010.02.078

Tammimäki, A., and Männistö, P. T. (2011). Effect of genetic modifications in the synaptic dopamine clearance systems on addiction-like behaviour in mice. Basic Clin. Pharmacol. Toxicol. 108, 2-8. doi: $\quad 10.1111 / j .1742-7843.2010$. 00647.x

Torrance, E. (1974). Differences are not deficits. Teach. Coll. Rec. 75, 471487.

Tsakanikos, E., and Claridge, G. (2005). More words, less words: verbal fluency as a function of 'positive'and 'negative' schizotypy. Pers. Individ. Dif. 39, 705-713. doi: 10.1016/j. paid.2005.02.019

Wang, Y.-C., He, B.-H., Chen, C.-C., Huang, A. C. W., and Yeh, Y.-C. 
(2012). Gender differences in the effects of presynaptic and postsynaptic dopamine agonists on latent inhibition in rats. Neurosci. Lett. 513, 114-118. doi: 10.1016/j.neulet. 2012.01.047

White, H. A., and Shah, P. (2011). Creative style and achievement in adults with attention-deficit/hyperactivity disorder. Pers. Individ. Dif. 50, 673-677. doi: 10.1016/j.paid.2010. 12.015

Young, S., Morris, R., Toone, B., and Tyson, C. (2007). Planning ability in adults with attention- deficit/hyperactivity disorder. Neuropsychology 21, 581-589. doi: 10. 1037/0894-4105.21.5.581

Zhong, S., Israel, S., Shalev, I., Xue, H., Ebstein, R. P., and Chew, S. H. (2010). Dopamine D4 receptor gene associated with fairness preference in ultimatum game. PLoS One 5:e13765. doi: 10.1371/journal. pone. 0013765

Conflict of Interest Statement: The authors declare that the research was conducted in the absence of any com- mercial or financial relationships that could be construed as a potential conflict of interest.

Received: 01 May 2013; accepted: 06 August 2013; published online: 26 August 2013.

Citation: Mayseless N, Uzeforsky F Shalev I, Ebstein RP and ShamayTsoory SG (2013) The association between creativity and $7 R$ polymorphism in the dopamine receptor D4 gene (DRD4). Front. Hum. Neurosci. 7:502. doi: 10.3389/fnhum.2013. 00502
This article was submitted to the journal Frontiers in Human Neuroscience. Copyright $\odot 2013$ Mayseless, Uzefovsky, Shalev, Ebstein and Shamay-Tsoory. This is an open-access article distributed under the terms of the Creative Commons Attribution License (CC BY). The use, distribution or reproduction in other forums is permitted, provided the original author(s) or licensor are credited and that the original publication in this journal is cited, in accordance with accepted academic practice. No use, distribution or reproduction is permitted which does not comply with these terms. 